\title{
Further Development of Testing Procedures for High Temperature Surface Tension Measurements
}

\author{
Enrica Ricci, Donatella Giuranno, and Natalia Sobczak
}

(Submitted May 19, 2013; in revised form June 4, 2013; published online July 9, 2013)

\begin{abstract}
A new testing procedure combining in one test two methods for surface tension measurements of liquid metals [the pendant drop (PD) and the sessile drop] and carried out in the same device is discussed. The attention is focused on methodological aspects of the PD method due to the novelty of its application for high temperature metallic systems. It has been claimed that under the conditions applied in the present study, this method can be considered as a quasi-containerless one. Surface tension measurements of pure $\mathrm{Cu}, \mathrm{Ni}, \mathrm{Al}$, and $\mathrm{Fe}$ performed using the new procedure are described. To confirm the validity of this procedure, the experimental results are discussed in the framework of the available literature data, particularly those obtained by the containerless methods.
\end{abstract}

Keywords liquid metals, pendant/sessile drop combined method, surface tension

\section{Introduction}

For high melting point metals containing reactive elements, the possibilities to measure surface tension are very limited. The most commonly used methods are the support-assisted or container-assisted ones, namely the sessile drop (SD) method and a variant of it, the large drop (LD) method (Ref 1) (Fig. 1a and $b$, respectively). However, the high melting temperature and the chemical reactivity, featured by the majority of metal systems for high-tech applications, increase the experimental difficulties of these ground-based techniques, thus lowering the measurements' accuracy. The inaccuracy can be caused by numerous sources of errors such as those due to the determination of the liquid metal density and the presence of impurities coming from the container or from the environment. To overcome these problems, the proper selection of the container material is a critical stage, often performed after a preliminary study of its wetting and reactivity in contact with high melting point metals (Ref 2-4). Therefore, only a few methods are really suitable for accurate measurements of the thermophysical properties at high temperatures using non-contact techniques. One of them is certainly the containerless electromagnetic levitation-oscillating drop (EML-OD) method (Ref 5).

Recently, a new quasi-containerless procedure has been proposed to measure the surface tension of very high melting metallic systems (Ref 6,7). The procedure combines in one test two methods: the pendant drop (PD) and the SD. The combined

Enrica Ricci and Donatella Giuranno, Consiglio Nazionale delle Ricerche, Istituto per l'Energetica e le Interfasi (CNR-IENI), Via de Marini 6, 16149 Genova, Italy; and Natalia Sobczak, Center for High Temperature Studies, Foundry Research Institute, 73 Zakopianska Street, 30-418 Kraków, Poland. Contact e-mail: natalia.sobczak@ iod.krakow.pl.

procedure allows the performance of both $\mathrm{PD}$ and SD measurements under the same conditions and in the same advanced experimental complex that has been designed for investigations of capillarity phenomena at very high temperature (up to $2400 \mathrm{~K}$ ) (Ref 8 ). Using a contact heating procedure in the conventional SD method (Fig. 1a), the metallic sample and the substrate (support) are in contact when heated from room temperature to the experimental one as well as during testing at that temperature. In the PD method (Fig. 1c), a metal, placed in a refractory capillary (container), is fast heated to the required temperature and immediately squeezed through a hole in the capillary to form a liquid metal drop. In contrast to the SD techniques (i.e., the conventional one and its LD modification shown in Fig. 1a and b, respectively), during surface tension measurements, the PD contacts the capillary at its tip only (Fig. 1c, d).

The PD is a well-known classical method used for surface tension measurements since the early works by Bashforth and Adams (Ref 9) and Adreas et al. (Ref 10). Particularly, it is widely used in ambient temperature liquid state materials science for non-metallic systems such as water or organic liquids. However, following the review by Keene (Ref 11), only a few reports are available on the conventional (using a capillary) PD measurements of surface tension of metals and they are limited to low melting temperature metals such as mercury (234 K) (Ref 12), gallium (303 K) (Ref 13), and selenium (494 K) (Ref 14). At the same time, it is often accepted that the PD method is one of the most convenient, versatile, and accurate solutions to measure the surface tension of refractory metals (Ref 15). To do this, the surface tension is determined from the weight of the detached drops produced in the PD tests. This method is known as the drop weight (DW) method or more precisely as the PD/DW method. From Keene's review (Ref 11), surface tension data are available for a large family of pure metals, including $\mathrm{Cu}, \mathrm{Co}, \mathrm{Cr}, \mathrm{Fe}, \mathrm{Gd}, \mathrm{Ge}, \mathrm{Hf}, \mathrm{Ir}$, Mo, Mn, Nb, Ni, Os, Pd, Pt, Pl, Re, Rh, Ro, Si, Ta, Ti, U, W, V, and $\mathrm{Zr}$. For a few of them, characterized by extremely high melting temperature, it is the only method that makes possible the surface tension measurements, i.e., Hf $(2500 \mathrm{~K})$, Ir $(2716 \mathrm{~K}), \mathrm{Nb}(2740 \mathrm{~K}), \mathrm{Os}(3300 \mathrm{~K}), \operatorname{Re}(3453 \mathrm{~K})$, 
Ru $(2523 \mathrm{~K})$, Ta $(3287 \mathrm{~K}), \mathrm{U}(1405 \mathrm{~K}), \mathrm{V}(2175 \mathrm{~K})$, W $(3653 \mathrm{~K})$, and $\mathrm{Zr}(2125 \mathrm{~K})$. However, for refractory metals, the $\mathrm{PD} / \mathrm{DW}$ procedure forming the PD differs substantially from the conventional PD method (Ref 16) because instead of a capillary tube with a liquid, it involves melting the end of a metal rod with an electron beam (Fig. 1e) to form a PD under the ultrahigh vacuum (UHV) conditions (Ref 17): The surface tension is determined from the weight of the detached drops. On the one hand, the PD/DW method enables reaching extremely high temperatures with an electron beam when molten metal is in contact only with its own solid (no contamination from a container). However, the PD/DW can be applied only at temperatures just near the melting point of the metal rod. Thus, it is not suitable for investigation of composition and/or temperature dependences of the surface tension of most metallic systems. It should be stressed that the $\mathrm{PD} / \mathrm{DW}$ data on the surface tension at melting temperatures are available for a number of pure refractory metals as well as for a few pure metals of much lower melting points (Bi, Zn, Cd) (Ref 11), but there are no data for the conventional PD method, besides $\mathrm{Hg}, \mathrm{Ga}$, and $\mathrm{Se}$.

For extremely high temperature applications, supplementary improvement of the PD method was proposed by Thiessen and Man (Ref 18). They applied a containerless melting of the end of a high purity metal rod ( $\mathrm{Zr}$ ) by bombardment with an electron beam to form a PD under UHV conditions together with the digitization of the $\mathrm{PD}$ profile, captured by a CCD, to compute the surface tension. However, similar to the PD/DW method, application of this improved PD procedure is limited to near melting temperature only and it is rather suitable for pure metals, but not for alloys, as suggested by Thiessen and Man (Ref 18).

The PD/SD combined method discussed in this study is providing further development of testing procedures for high temperature surface tension measurements. For the first time, this procedure was successfully applied for the determination of the surface tension of a class of reactive metal systems, the liquid $\gamma$-TiAl-based alloys, the high melting temperature of which is responsible for serious methodological problems, as reported in Ref 6 . The idea of the proposed testing procedure was based on the assumption that, even for very reactive systems, there are certain conditions and a period of time when reactivity is negligible and, therefore, a significant improvement in accuracy and reliability of measurements can be obtained. In order to reach such conditions, both the area of contact and the time of contact between the metal and the container should be considerably decreased. Such conditions can be achieved by applying a capillary (a very small area of contact of the drop with the container at the tip of a capillary only), together with fast manipulating of liquid metal (drop squeezing, movement, and deposition) at high temperature under vacuum or protective atmosphere, accompanied by fast recording of the drop images with a high-speed CCD camera.

Additional improvement in testing conditions can be attained by suppression of the interaction between the melt and the capillary. For example, even a very thin, nanoscalesized native oxide film on a metal sample that usually creates many problems in the investigation of capillary properties at high temperature (Ref 19), in this particular case, may be very helpful as a natural barrier to chemical reactions between the metal and the internal wall of the container. This approach was successfully applied in Ref 6 for surface tension measurements of highly reactive $\mathrm{TiAlNb}$ and TiAlTa alloys, taking advantage of the fact that the surface of these samples is covered with a native alumina layer which slows down chemical reaction of the alloy with the alumina capillary used. Additionally, in order to produce oxide-free droplets, necessary for reliable measurements of surface tension, the metal drop was in situ cleaned directly in the vacuum chamber (Ref 20) by squeezing the metal through the alumina capillary of a special design, allowing mechanical removal of an oxide film at the sharp internal edges of the capillary (Ref 19) (Fig. 1d).

Despite the fact that in the proposed procedure the contact of the liquid metal with a capillary is unavoidable, the time of the drop/capillary contact at the capillary tip can be limited to a few seconds needed for drop stabilization. As demonstrated in our previous work (Ref 6) using a high-resolution and high-speed camera (up to 2000 frames/s), a large number of high quality drop images, indispensable for reliable surface tension calculations, are recorded.

Seeking a practical embodiment of the above ideas, an advanced experimental complex has been designed which enables studying the capillary phenomena in liquid metals at high temperature and under high vacuum or protective atmosphere using different testing methods and procedures, as described in detail in Ref 19 and 20.

In this work, attention has been focused particularly on methodological aspects of the proposed combined PD/SD method due to the novelty of its application to very high temperature metallic systems. In fact, on the basis of promising results obtained for the liquid $\gamma$-TiAl-based alloys (Ref 6), the verification of certain aspects of the new methodology for its optimization seemed to be necessary. For this reason, it was decided to measure the surface tension of a few pure metals taken as reference materials due to availability of extensive experimental results reported in the literature.

Measurements of surface tension of pure $\mathrm{Cu}, \mathrm{Ni}, \mathrm{Al}$, and $\mathrm{Fe}$ obtained using the same experimental facility and by the combined $\mathrm{PD} / \mathrm{SD}$ testing procedure are presented. To confirm the validity of the new quasi-containerless method, the results are discussed in the framework of the available literature data obtained by different methods, particularly by the containerless ones such as the EML-OD method.

Thus, the revision of literature data as well as new reference data for the metals selected is beyond the scope of this work.

\section{Materials and Methods}

Experimental complex, described in detail in Ref 8, equipped with several manipulators, allowing application of different testing procedures as reported in Ref 6, 7, 19, and 20, was used in this study. Special mention must be made of the fact that the design of the experimental complex, built from a few independent and directly interconnected vacuum chambers, allows loading and removing of the metal samples, the substrates, and the capillaries without the necessity to open the working (high temperature) vacuum chamber.

Surface tension measurements have been performed in a resistance furnace with a Ta heating element surrounded with Ta and Mo isolation screens. All elements of manipulators as well as the experimental table (as a support for a substrate, Fig. 1a, b), introduced inside the Ta heater during the tests, were also made from Ta. The capillary (container), with a hole diameter of $1.1 \mathrm{~mm}$, was produced from alumina powder of 99.995\% purity without any sintering aids. 
High purity $(99.999 \%) \mathrm{Cu}, \mathrm{Ni}, \mathrm{Al}$, and $\mathrm{Fe}$ metals were used to prepare the samples. Directly before loading into the vacuum chamber of the furnace, the metal samples of desired volume (about $0.5 \mathrm{~cm}^{3}$ ) were mechanically cleaned by scratching and then chemically rinsed with pure ethanol in an ultrasonic bath. Next, the selected sample was placed in the $\mathrm{Al}_{2} \mathrm{O}_{3}$ polycrystalline capillary and introduced into a vacuum chamber. After melting and reaching the required temperature, the metal was squeezed through the capillary to produce a PD. The surface tension was measured as a function of temperature in steps of $50 \mathrm{~K}$. For each temperature step, the drop's images were recorded for about $10 \mathrm{~min}$ by a high-speed digital camera, equipped with high quality photographic lens allowing a high resolution at optical wavelength. Since the main sources of error are the intrinsic TV-camera distortion, the discretization process, and the evaluation of the system magnification factor, all the optical devices were mounted on an optical bench. The digital images were analyzed to obtain numerical data points of the contour of the drop. Dedicated software packages have been developed (Ref 21) capable of obtaining surface tension data in real time together with other experimental parameters (i.e., drop shape and size, surface area, contact angle). In order to get better repeatability of the measurements, the focusing, the focal length, and the diaphragm of the optical system were kept fixed. Considering that the knowledge of the magnification factor is essential for deriving the real drop profile coordinates from the acquired ones, the magnification factor was calculated individually for each image. The surface tension was calculated using an improved version of the Maze and Burnet algorithm (Ref 22).

In this study, the measurements by the PD method were carried out in a few steps. First, the apparatus was heated up to the measurement temperature keeping the capillary in the low temperature zone of the UHV chamber. Next, using a special manipulator, the capillary was introduced into the high temperature zone, where liquid metal was squeezed through the capillary to form a drop with appropriate dimensions allowing the correct profile acquisition.

A similar procedure was applied when the liquid metal was dispensed by the capillary on a flat substrate, forming a SD (Fig. 1a), or into a crucible (Fig. 1b) for the measurements by the LD method (Ref 1-3). In particular, in this study, sapphire plates and crucibles cut from a (0001) single-crystal $\alpha-\mathrm{Al}_{2} \mathrm{O}_{3}$ rod, pretreated for $2 \mathrm{~h}$ at $1300 \mathrm{~K}$ in vacuum, have been used.

It should be underlined that at very high temperatures, manipulating a capillary located inside an UHV chamber using outside control may create several technical problems. Particularly tricky is placing the capillary in perfect vertical position and obtaining drops of suitable dimensions that will remain fixed at the capillary orifice. Moreover, the control of the size and stability of a drop formed at a capillary tip is particularly difficult because it depends not only on the metal properties (density, surface tension, viscosity) but also on the size of the capillary hole.

However, the capillary size does not influence the surface tension values (Ref 23). The size of the capillary used in this work (i.e., $1.1 \mathrm{~mm}$ diameter hole) was satisfactory in obtaining stable drops of $\mathrm{Al}, \mathrm{Ni}$, and $\mathrm{Fe}$, but it was not sufficient to get $\mathrm{Cu}$ drops of appropriate dimensions due to an unfavorable ratio between surface tension and density.

Furthermore, the high temperature emissivity is another factor affecting the drop image quality, thus making the measurements difficult. Therefore, IR cut-off filters were used for this purpose.

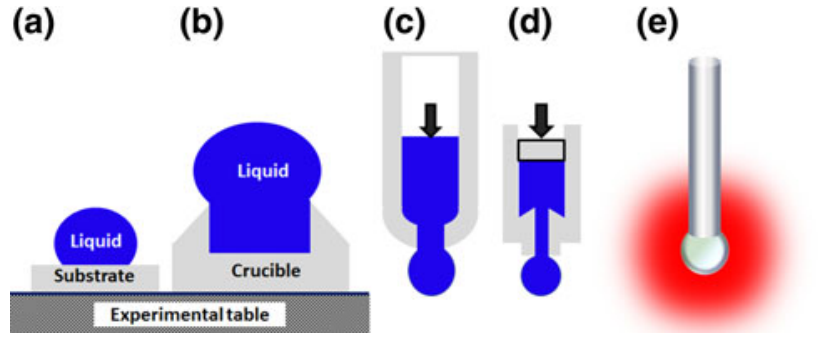

Fig. 1 Schematic presentation of methods for surface tension measurements: (a) conventional SD method; (b) LD; (c, d) conventional PD using a capillary; (d) improved design of internal shape of a capillary to remove native oxide film from a metal liquid (Ref 19); (e) PD accompanied with melting of the metal rod end with ion beam

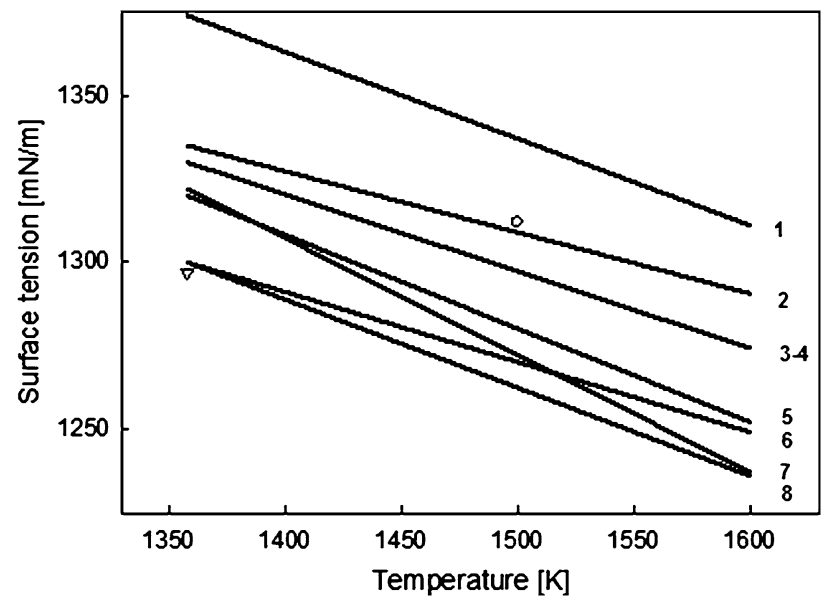

Fig. 2 Surface tension of liquid $\mathrm{Cu}$ measured by PD method in this work $(\bigcirc)$. For comparison, the literature data on the surface tension of $\mathrm{Cu}$ obtained by other techniques are also plotted: 1- "suggested" data (Ref 11); 2-LD method (Ref 32); 3-4-EML-OD method (Ref 33) and "mean values" as reported in Ref 11; 5- "adopted data" (Ref 24); 6-SD method (Ref 36); 7-SD (Ref 35); 8-EMLOD (Ref 37); (V) PD/DW method (Ref 34)

For the measurements by both PD and SD (or LD) performed in this work, the final values of the surface tension were calculated as an average of all the data measured at each temperature. The calculated experimental error of the surface tension measurements was less than $1 \%$.

\section{Results and Discussion}

A large number of experimental data are available in the literature for pure $\mathrm{Cu}, \mathrm{Ni}, \mathrm{Al}$, and $\mathrm{Fe}$ that have been chosen as reference materials to check the applicability of the new procedure for high temperature measurements of metallic systems (Ref 11, 24-51). The surface tension values obtained in this work were preferably compared with the most recent data, in particular with those reported in the recent review of Mills and Su (Ref 24). Special attention has been paid to the comparison with the literature data obtained by the containerless EML-OD method.

\subsection{Copper}

The first attempt to form a PD was done with $\mathrm{Cu}$. Measurements were carried out under an atmosphere of flowing high purity N5.2 argon (99.9992\%) from Air Products Co 
$\left(P_{\text {tot }}=8.5 \times 10^{4} \mathrm{~Pa}\right)$. The presence of a Ta heater, acting as an oxygen getter, assured an oxygen partial pressure inside the test chamber equal to $P_{\mathrm{O}_{2}}=10^{-8} \mathrm{~Pa}$ at the testing temperature $T=1500 \mathrm{~K}$

However, only at $T=1500 \mathrm{~K}$, a metal drop stable in dimensions was formed allowing a reliable acquisition of its profile coordinates. The resulting value of surface tension is shown in Fig. 2.

At higher temperatures, several technical problems, mainly related to the high temperature of the experiment and initially non-optimized setup of the PD system, occurred during the experiment on liquid $\mathrm{Cu}$. Due to these problems, it was difficult to get $\mathrm{Cu}$ drops of appropriate dimensions and to keep them pendant for the time necessary to complete the acquisition procedure. Indeed, due to an unfavorable ratio between surface tension and density, increasing the drop size made the $\mathrm{Cu}-\mathrm{PD}$ fall down after only a few seconds before reaching the appropriate dimensions. These difficulties made impossible also the measurements by the LD method due to the inability to dispense sufficient amount of material into the crucible, since at that time the size of both the capillary and the crucible was not optimized, but this task is beyond the scope of the present research work.

Nevertheless, the value obtained at $T=1500 \mathrm{~K}$ agrees well with the corresponding linear fit of the surface tension values of $\mathrm{Cu}$ measured by the LD method in the temperature range of 1423-1523 K (Ref 32). These last values are included among the suggested values of Keene's review (Ref 11) and those defined as "adopted" in the recent review of Mills and $\mathrm{Su}$ (Ref 24). Furthermore, our data are also in conformity with the recent results obtained with the containerless EML-OD method (Ref 33). In particular, it should be noted that the latter overlaps the linear fit of the mean values of $\mathrm{Cu}$ surface tension as reported in Ref 11. In Fig. 2, the surface tension value of $\mathrm{Cu}$, measured at the melting point by the PD/DW method (Ref 34), is also shown for comparison.

\subsection{Nickel}

In the case of liquid nickel, the measurements were performed at $T=1773 \mathrm{~K}$ under vacuum $\left(P_{\text {tot }} \leq 10^{-4} \mathrm{~Pa}\right)$ with a corresponding value of oxygen partial pressure $P_{\mathrm{O}_{2}}<$ $10^{-7} \mathrm{~Pa}$ (and $P_{\mathrm{H}_{2} \mathrm{O}}<10^{-6}-10^{-5} \mathrm{~Pa}$ ), estimated by mass spectrometry using real time measurements by means of a quadrupole residual gas analyzer ( $\operatorname{Ref} 8,20)$. Contrary to $\mathrm{Cu}$, the experiments on $\mathrm{Ni}$ have faced fewer difficulties in forming stable PD. However, the very high emissivity both of the furnace elements and the $\mathrm{Ni}$ sample above its melting point $(1726 \mathrm{~K})$ caused new problems in getting sharp drop images. In this case, application of a special filter was helpful for the extremely difficult setting up of the optical line.

Figure 3 shows the surface tension values of Ni measured in the temperature range of 1773-1923 $\mathrm{K}$ in comparison with the literature data obtained using different techniques (Ref 24, 38, 39). The linear fitting of surface tension values of pure $\mathrm{Ni}$ obtained in this work is in agreement with the literature data. The surface tension temperature coefficient is very close to that of the linear relationships suggested by Keene (Ref 11) and defined as "adopted" by Mills and Su in Ref 24. In particular, a good agreement was found with the results obtained by the containerless EML-OD method reported by Brillo and Egry in Ref 38, even if the absolute values obtained here by PD measurements are higher.

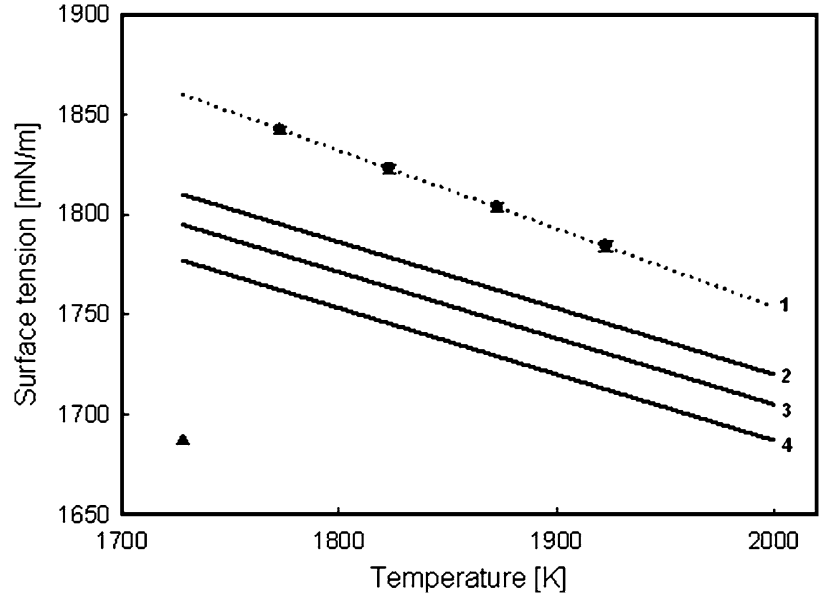

Fig. 3 Surface tension of liquid Ni measured by PD method in this work (-). For comparison, the literature data on the surface tension of Ni obtained by other techniques are also plotted: 1-linear fit of the PD data; 2-SD method (Ref 35); 3- "adopted data" (Ref 24) and "mean values" (Ref 11); 4-EML-OD method (Ref 38); (A) PD/DW method (Ref 39)

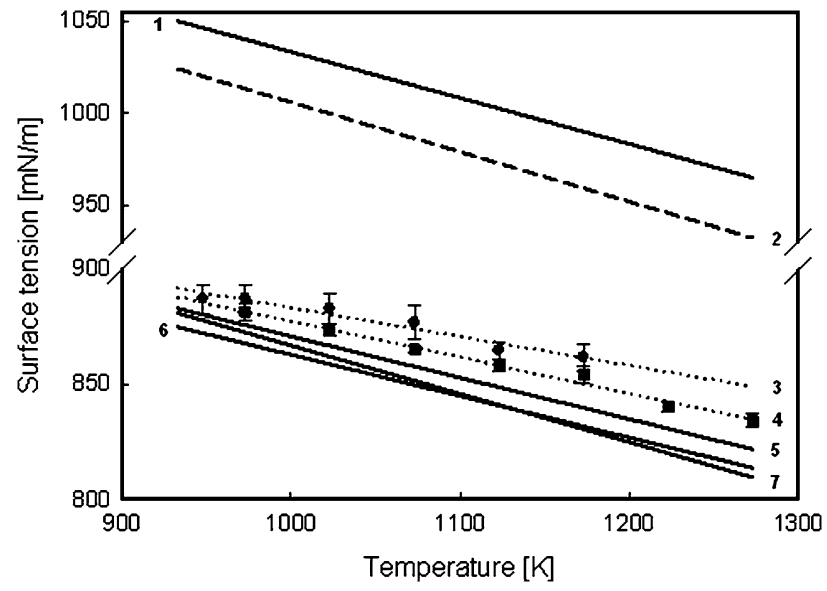

Fig. 4 Surface tension of liquid Al measured in this work by the combined method: PD method $(O)$ and LD method $(\boldsymbol{\square})$. For comparison, the literature data on the surface tension of $\mathrm{Al}$ obtained by other techniques are also plotted: 1-oxygen-free values suggested by Ref 24; 2-LD/AD method (Ref 51); 3 -linear fit of PD data obtained in this work; 4-linear fit of LD data obtained in this work; 5-LD (Ref 50); 6-EML-OD method (Ref 42); 7-oxygen saturated values suggested in Ref 24; 8-literature "mean values" $(\operatorname{Ref} 11) ;(\nabla)$ the highest value from Ref 49

As in the case of $\mathrm{Cu}$, a value of the $\mathrm{Ni}$ surface tension measured by the PD/DW method was found in the literature (Ref 39). For comparison, this value is shown in Fig. 3.

\subsection{Aluminum}

The favorable combination of the ratio between surface tension and density of liquid Al, together with a capillary suitably sized, allowed getting stable drops with appropriate dimensions. Thus, reliable data on the aluminum surface tension were obtained by application of the combined PD/LD method, taking measurements in the temperature range of 973-1273 K under a vacuum. The measurements were performed under a total pressure of $P_{\text {tot }}=10^{-4} \mathrm{~Pa}$ with a corresponding value of oxygen 
partial pressure $P_{\mathrm{O}_{2}}=1.3 \times 10^{-7} \mathrm{~Pa}\left(P_{\mathrm{H}_{2} \mathrm{O}}=10^{-6}-10^{-5} \mathrm{~Pa}\right)$, estimated by the mass spectrometry during Al surface tension measurements. Figure 4 shows the surface tension values of $\mathrm{Al}$ measured in this work, simultaneously by PD and LD (in a sapphire crucible). Each value represents the average of a large number of measurements performed under isothermal conditions, maintained for at least $10 \mathrm{~min}$, so as to meet the equilibrium conditions. In spite of the experimental difficulties caused by the high temperature and the IR emission, the obtained results for $\mathrm{Al}$ can be considered as successful for the purpose of this study. The values were compared with the literature data obtained by other techniques (Ref 24, 47-52).

The surface tension data obtained by PD and LD are in good agreement with most of the literature data, in particular with those obtained by containerless methods (Ref 42 ). The values achieved by PD are the highest and show the temperature coefficient to be in good agreement with the literature data.

For comparison, two other relationships are shown in Fig. 4 (marked with 1 and 2). Relationship 1 corresponds to the average of the few highest values reported in the literature and assumed as the oxygen-free values (Ref 24). The second one is the "low temperature" extrapolation of the values reported by Sarou-Kanian et al. (Ref 51), who measured the surface tension of $\mathrm{Al}$ in a temperature range of $1700-2100 \mathrm{~K}$ using the levitated drop/aerodynamic levitation (LD/AL) method. The highest value of the Al surface tension measured by Goumiri and Joud (Ref 49) is also shown.

\subsection{Iron}

Considering the favorable density/surface tension ratio, the combined procedure $\mathrm{PD} / \mathrm{SD}$ was also used to measure the surface tension of liquid iron at $T=1973 \mathrm{~K}$. In order to suppress liquid metal evaporation at high temperature, surface tension measurements were performed under static inert atmosphere $P_{\text {tot }}=10^{5} \mathrm{~Pa}$ of N5.2 argon $(99.9992 \%)$ from Air Products Co. As a first step, a SD was produced by squeezing the liquid metal through polycrystalline alumina capillary onto a single-crystal $\alpha-\mathrm{Al}_{2} \mathrm{O}_{3}(0001)$ plate. The next drop squeezed was kept pendant and both droplets were maintained at a constant temperature of $1973 \mathrm{~K}$ (Fig. 5) for 10 minutes to measure surface tension.

It should be highlighted that the contact angle value $\theta=108^{\circ}$ was assumed by the freshly deposited SD of liquid iron on the sapphire plate. Interaction phenomena occurring at the $\mathrm{Fe} / \mathrm{Al}_{2} \mathrm{O}_{3}$ interface are well known (Ref 53): The reaction between the substrate and the droplet is the driving energy at the triple line, thereby affecting the surface tension reliability.

On the contrary, taking advantage of the lack of contact between the metal and the internal wall of the capillary, the surface tension data obtained by processing the droplet profiles of liquid iron in the pendant shape can be suitably compared with the literature. In particular, the surface tension value measured at $T=1973 \mathrm{~K}$ (Fig. 6) is very consistent both with the suggested values of Keene's review (Ref 11) and those recommended in the recent review of Mills and $\mathrm{Su}$ (Ref 24). Moreover, the surface tension value of liquid iron obtained by the PD method in this study is in reasonable agreement with the one measured by Brillo and Egry (Ref 38) using the EML-OD method.

The results obtained in the present study and the most recent and representative literature data are summarized in Table 1. The experimental conditions and the methods applied for the measurements of surface tension $(\gamma)$ are collected together with

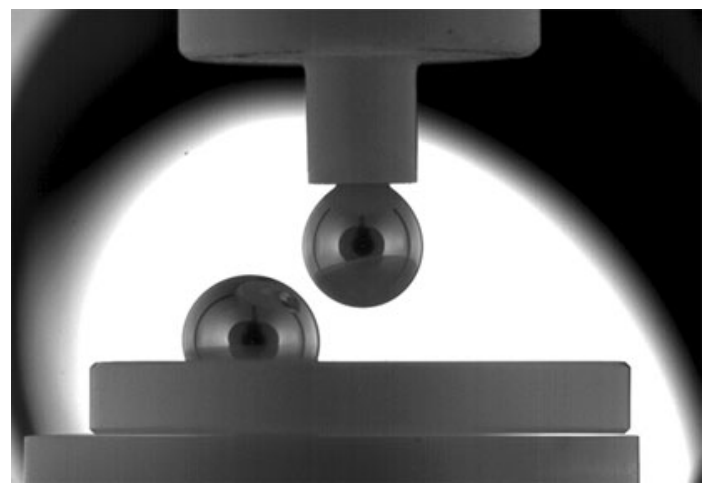

Fig. 5 Image of an Fe-PD in the presence of a SD formed in the experimental complex apparatus at $T=1973 \mathrm{~K}$

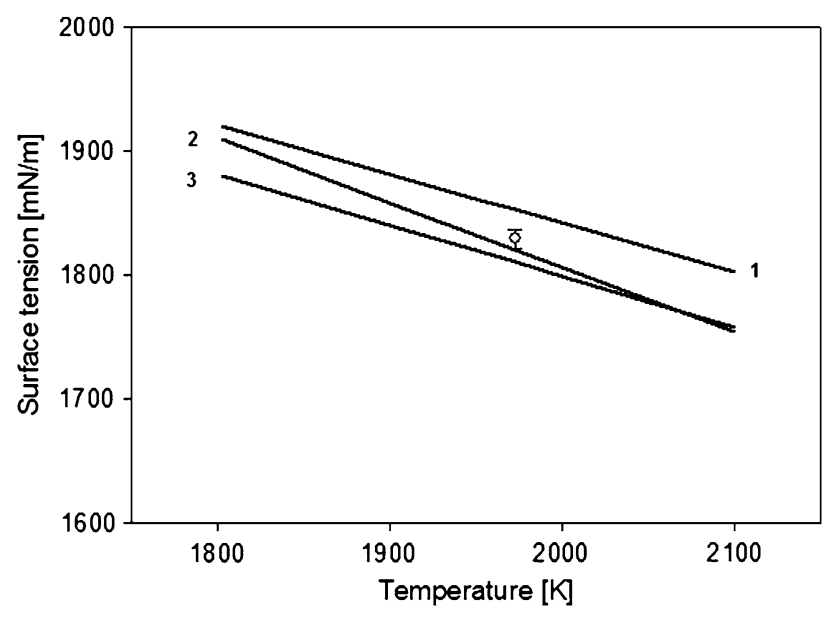

Fig. 6 Surface tension of liquid Fe measured in this work by PD method $(\bigcirc)$. For comparison, the literature data on the surface tension of Fe obtained by other techniques are also plotted: 1-EMLOD method (Ref 38); 2-recommended data (Ref 24); 3-adopted data $(\operatorname{Ref} 11)$

the experimental values and, when available, the surface tension-temperature dependence (linear fitting) is also given.

\section{Summary}

In order to test the applicability of a new procedure aimed to measure the surface tension of very high melting, high reactive metal systems, the surface tension of pure $\mathrm{Cu}, \mathrm{Ni}, \mathrm{Al}$, and $\mathrm{Fe}$ was measured. The proposed combined procedure consists of using two techniques (the PD and the SD/LD) in one test in the same advanced experimental complex that has been designed for investigations of high temperature capillarity phenomena.

The analysis of the results obtained highlights a good agreement of the surface tension measurements, in particular with those obtained by the containerless EML-OD method. The difference in results is less than $1.5 \%$, except for $\mathrm{Ni}$, for which $\mathrm{PD}$ values are by about 5\% higher. Following the aim of this work, it may be concluded that the results obtained confirm the feasibility of the new testing procedure recently proposed by the authors and for the first time applied for surface tension measurements of TiAlTa and TiAlNb alloys. This procedure, named the PD/SD combined method, shows several advantages 
Table 1 Surface tension of the selected liquid metals measured in this work (indicated by *). For comparison, the literature data on the surface tension obtained by containerless EML-OD method are also reported

\begin{tabular}{|c|c|c|c|c|}
\hline Pure metal & Temperature, $\mathbf{K}$ & Atmosphere & $\begin{array}{c}\text { Surface tension, } \mathrm{mN} / \mathrm{m} \\
\gamma\left(T_{\mathrm{m}}\right)+\gamma^{\prime}\left(T-T_{\mathrm{m}}\right)\end{array}$ & Method \\
\hline \multirow[t]{3}{*}{$\mathrm{Cu}$} & 1500 & $\mathrm{Ar}$ & $\gamma_{1500}=1312$ & $\mathrm{PD}^{*}$ \\
\hline & $1423-1523$ & $\mathrm{Ar}$ & $\gamma=1339 \pm 3.1-0.18(T-1358)$ & LD $(\operatorname{Ref} 32)$ \\
\hline & $1440-1725$ & $\mathrm{He}$ & $\gamma=1330 \pm 2.7-0.23(T-1358)$ & EML-OD (Ref 37) \\
\hline \multirow[t]{2}{*}{$\mathrm{Ni}$} & $1773-1923$ & Vacuum & $\gamma=1860 \pm 2.2-0.39(T-1728)$ & $\mathrm{PD}^{*}$ \\
\hline & $1400-1970$ & $\mathrm{He}$ & $\gamma=1770-0.33(T-1728)$ & EML-OD (Ref 38) \\
\hline \multirow[t]{3}{*}{$\mathrm{Al}$} & $943-1173$ & Vacuum & $\gamma=892 \pm 5.5-0.13(T-933)$ & $\mathrm{PD}^{*}$ \\
\hline & $973-1273$ & Vacuum & $\gamma=888 \pm 2.5-0.16(T-933)$ & $\mathrm{LD}^{*}$ \\
\hline & $893-1423$ & $\mathrm{He}$ & $\gamma=881-0.21(T-933)$ & EML-OD (Ref 42) \\
\hline \multirow[t]{2}{*}{$\mathrm{Fe}$} & 1973 & $\mathrm{Ar}$ & $\gamma_{1973}=1829$ & $\mathrm{PD}^{*}$ \\
\hline & $1763-2073$ & $\mathrm{He}-\mathrm{H}_{2}$ & $\gamma=1920-0.397(\mathrm{~T}-1811)$ & EML-OD (Ref 38) \\
\hline
\end{tabular}

$P D$ pendant drop method, $L D$ large drop method, $E M L-O D$ electromagnetic levitation-oscillating drop method

and some drawbacks. The advantages are mainly due to the way of forming the liquid metal drop, because due to the formation of a PD by squeezing the liquid metal from a capillary and subsequent fast deposition of the drop on a substrate (SD), there are the following benefits:

- the droplet squeezed through a capillary is free of primary native oxide film, affecting the reliability of surface tension measurements; this film is difficult to remove by any other way, particularly for oxidizable alloys;

- the same oxide film plays the role of a barrier that might reduce or even prevent the interaction of the metal with the capillary during heating;

- the contact of freshly squeezed liquid metal with either the capillary or a substrate is very short (a few seconds), compared to the conventional SD procedure;

- similar to the LD method, the dispensed droplet deposited on a substrate has a high symmetry, thus improving reliability of surface tension measurements by the conventional SD procedure;

- the PD procedure can be combined with the LD method by squeezing several small droplets into a crucible in order to get the total liquid volume required for LD measurements.

The comparison between the surface tension values of the few pure metals investigated in this work and the corresponding literature data is encouraging due to the satisfactory agreement. In addition, considering the good results previously obtained for the $\gamma$-TiAl-based alloys, a very high temperature and highly reactive technologically relevant class of structural materials, further applications of this experimental approach to study high melting point metal systems can be envisaged.

Nevertheless, in view of the application of this new experimental approach to study metal systems that are both highly reactive and oxidizable, further developments in the setup of the PD apparatus used in the proposed procedure are required. In this way, it is expected to get additional improvements in the accuracy and reliability of surface tension measurements. In fact, the performance of the experiments carried out in this work showed some drawbacks:

- The use of alumina as a material for the capillary, due to the complexity of the design of its inner part and the manufacturing techniques currently available, is limitative.
Therefore, in order to obtain better performances and accuracy of high temperature measurements, there is a justified need to have the possibility of different refractory materials available, depending on the metal system to be measured and limiting the mutual reactivity between the metal and the container (support).

- Controlling the size of the PD is critical. The only way to obtain a real reproducibility of the measurements is by preventing the drops from falling during the experiments and by insuring a sufficient and stable drop volume to enable the drop profile acquisition to be effective. This problem is complex because it depends not just on physical variables and their temperature dependence but is also linked to technical factors such as the dimensions of the capillary. From this point of view, both the capillary internal volume and its hole size should be optimized individually for each metal system. Although some tricks have been adopted (such as the special design of the interior of the capillary, the controlled atmosphere, the presence of a getter), the quantitative determination of the oxygen present in the test chamber, particularly under flowing gas conditions, would allow an assessment of the actual oxidation conditions of the test system.

To overcome these drawbacks, needed for further development of testing methods and procedures for high temperature surface tension measurements, the additional improvements in the design of the experimental devices involve the following:

(i) the use of new advanced refractory materials with both high chemical and high dimensional stability suitable for ultrahigh temperature measurements of liquid metallic systems;

(ii) the development of new testing procedures allowing a better control of PD size;

(iii) the control and real time monitoring of the oxygen content in the vicinity of the testing sample (drop).

\section{Acknowledgments}

The authors acknowledge the financial support provided by the Ministry of Science and Higher Education of Poland (Project No. 721/N-NICKEL/2010). 


\section{Open Access}

This article is distributed under the terms of the Creative Commons Attribution License which permits any use, distribution, and reproduction in any medium, provided the original author(s) and the source are credited.

\section{References}

1. Yu.V. Naidich, Progress in Surface and Membrane Science, Vol 14, D.A. Cadenhead and F. Danielli, Eds., Academic Press, New York, 1981, p 353-484

2. E. Ricci, E. Arato, A. Passerone, and P. Costa, Oxygen Tensioactivity on Liquid-Metal Drops, Adv. Coll. Interf. Sci, 2005, 117(1-3), p 15-32

3. I. Egry, E. Ricci, R. Novakovic, and S. Ozawa, Surface Tension of Liquid Metals and Alloys-Recent Developments, Adv. Colloid Interf. Sci., 2010, 159, p 198-212

4. D. Giuranno, A. Tuissi, R. Novakovic, and E. Ricci, Surface Tension and Density of Al-Ni Alloys, J. Chem. Eng. Data, 2010, 55(9), p 3024-3028

5. D.M. Herlach, R.F. Cochrane, I. Egry, H.J. Fecht, and A.L. Greer, Containerless Processing in the Study of Metallic Melts and Their Solidification, Int. Mater. Rev., 1993, 38, p 273-347

6. R. Nowak, T. Lanata, N. Sobczak, E. Ricci, D. Giuranno, R. Novakovic, D. Holland-Moritz, and I. Egry, Surface Tension of TiAl Based Alloys, J. Mater. Sci., 2010, 45, p 1993-2001

7. I. Egry, D. Holland-Moritz, R. Novakovic, E. Ricci, R. Wunderlich, and N. Sobczak, Thermophysical Properties of Liquid Al-Ti Based Alloys, Int. J. Thermophys., 2010, 31(4-5), p 949-965

8. N. Sobczak, R. Nowak, W. Radziwill, J. Budzioch, and A. Glenz, Experimental Complex for Investigations of High-Temperature Behaviour of Molten Metals in Contact with Refractory Materials, Mater. Sci. Eng., 2008, A495, p 43-49

9. F. Bashforth and J. Adams, An Attempt to Test the Theories of Capillary Action, Cambridge University Press, Cambridge, 1883

10. J.M. Andreas, E.A. Hauser, and W.B. Tucker, Boundary Tension by Pendant Drop, J. Phys. Chem., 1938, 42, p 1001-1019

11. B.J. Keene, Review of Data for the Surface-Tension of Pure Metals, Int. Mater. Rev., 1993, 38, p 157-192

12. T. Smith, Optical Constants of a Clean Mercury Surface as a Function of Temperature, J. Opt. Soc. Am., 1967, 57, p 1207-1210

13. G.J. Abbaschian, Surface Tension of Liquid Gallium, J. Less-Common Met., 1975, 40, p 329-333

14. K. Astakov, N. Penin, and E. Dobkina, Surface Tension and Density of Liquid Selenium, Zh. Fiz. Khim., 1946, 20, p 403-408 (in Russian)

15. B. Vinet, J.P. Garandet, and L. Cortella, Surface Tension Measurements of Refractory Liquid Metals by the Pendant Drop Method Under Ultrahigh Vacuum Conditions: Extension and Comments on Tate's Law, J. Appl. Phys., 1993, 73, p 3830-3834

16. T. Iida and R.I.L. Guthrie, The Physical Properties of Liquid Metals, Clarendon Press, Oxford, 1993

17. J.P. Garandet, B. Vinet, and P. Gros, Considerations on the Pendant Drop Method: A New Look at Tate's Law and Harkins' Correlation Factor, J. Colloid Interf. Sci., 1994, 165, p 351-354

18. D.B. Thiessen and K.F. Man, A Quasi-Containerless Pendant Drop Method for Surface Tension Measurements of Molten Metals and Alloys, Int. J. Thermophys., 1995, 16(1), p 245-255

19. N. Sobczak, R. Asthana, W. Radziwill, R. Nowak, and A. Kudyba, The Role of Aluminium Oxidation in the Wetting-Bonding Relationship of Al/Oxide Couples, Arch. Metall. Mater, 2007, 52(1), p 55-65

20. N. Sobczak, J. Sobczak, R. Asthana, and R. Purgert, The Mystery of Molten Metal, China Foundry, 2010, 7(4), p 425-437

21. L. Liggeri and A. Passerone, An Automatic Technique for Measuring the Surface Tension of Liquid Metals, High Technol., 1989, 7, p 80-86

22. C. Maze and G. Burnet, A Non-Linear Regression Method for Calculating Surface Tension and Contact Angle from the Shape of a Sessile Drop, Surf. Sci., 1969, 13(2), p 451-470

23. J.F. Padday, Surface and Colloid Science, Vol 1, E. Matijevic and F.R. Eirich, Eds., Wiley, New York, 1969

24. K. Mills and Y. Su, Review of Surface Tension Data for Metallic Elements and Alloys: Part 1-Pure Metals, Int. Mater. Rev., 2006, 51, p 329-351
25. Yu.V. Naidich and V.N. Eremenko, The Large-Drop Method for Determining Surface Tension and Density of Molten Metals at High Temperature, Fiz. Met. Metall., 1961, 11, p 883-888 (in Russian)

26. P. Laty, J.C. Joud, P. Desré, and G. Lang, Tension Superficielle d'Alliages Liquides Aluminium-Cuivre, Surf. Sci., 1977, 69(2), p 508520 (in French)

27. A. Kasama, T. Iida, and Z. Morita, Temperature Dependence of Surface Tension of Liquid Pure Metals, J. Jpn. Inst. Met., 1976, 40, p 10301038

28. B.J. Keene, K.C. Mills, A. Kasama, A. McLean, and W.A. Miller, Comparison of Surface Tension Measurements Using Levitated Droplet Method, Metall. Trans., 1986, 17B, p 159-162

29. A. Gallois and C.H.P. Lupis, Effect of Oxygen on Surface Tension of Liquid Copper, Metall. Trans., 1981, 12B, p 549-557

30. P.D. Ownby and J. Lui, Surface Energy of Liquid Copper and SingleCrystal Sapphire and the Wetting Behavior of Copper on Sapphire, J. Adhesion Sci. Technol., 1988, 2, p 255-269

31. K. Nogi, K. Oishi, and K. Ogino, Wettability of Solid Oxides By Liquid Pure Metals, Mater. Trans. JIM, 1989, 30, p 137-145

32. R. Novakovic, E. Ricci, D. Giuranno, and A. Passerone, Surface and Transport Properties of Ag-Cu Liquid Alloys, Surf. Sci., 2005, 576(13), p 175-187

33. S. Amore, J. Brillo, I. Egry, and R. Novakovic, Surface Tension of Liquid $\mathrm{Cu}-\mathrm{Ti}$ Binary Alloys Measured by Electromagnetic Levitation and Thermodynamic Modeling, Appl. Surf. Sci., 2011, 257(17), p 7739-7745

34. B.C. Allen, The Surface Tension of Liquid Transition Metals at Their Melting Points, Trans. Metall. Soc. AIME, 1963, 227, p 1175-1183

35. R. Brooks, I. Egry, S. Seetharaman, and D. Grant, Reliable Data for High-Temperature Viscosity and Surface Tension: Results from a European Project, High Temp. High Press., 2001, 33, p 631-637

36. J. Lee, W. Shimoda, and T. Tanaka, Surface Tension and Its Temperature Coefficient of Liquid Sn-X (X = Ag, Cu) Alloys, Mater. Trans., 2004, 45(9), p 2864-2870

37. J. Schmitz, J. Brillo, I. Egry, and R. Schmid-Fetzer, Surface Tension of Liquid Al-Cu Binary Alloys, Int. J. Mater. Res., 2009, 100, p 1529-1535

38. J. Brillo and I. Egry, Surface Tension of Nickel, Copper, Iron and Their Binary Alloys, J. Mater. Sci., 2005, 40(9-10), p 2213-2216

39. K.F. Man, Surface Tension Measurements of Liquid Metals by the Quasi-Containerless Pendant Drop Method, Int. J. Thermophys., 2000, 21(3), p 793-804

40. W.D. Kingery and M. Humenik, Surface Tension at Elevated Temperatures. I, J. Phys. Chem., 1953, 57, p 359-363

41. P. Kozakevitch and G. Urbain, Surface Tension of Pure Liquid Iron, Cobalt and Nickel at $1550^{\circ} \mathrm{C}$, J. Iron Steel Inst., 1957, 186, p 167-173

42. I. Egry, S. Schneider, I. Seyhan, and T. Volkmann, Surface Tension Measurements of High Temperature Melts, Trans. JWRI, 2001, 30, p 195-200

43. N. Eustathopoulos, J.C. Joud, P. Desre, and J.M. Hicther, The Wetting of Carbon by Aluminium and Aluminium Alloys, J. Mater. Sci., 1974, 9, p 1233-1242

44. N.A. Vatolin, O.A. Esin, V.F. Ukhov, and E.L. Dubinin, Tr. Inst. Metall. (Sverdlovsk), 1969, 18, p 73 (in Russian) cited in S.V. Lukin, V.I. Zhuchkov, and N.A. Vatolin, Surface Tension, Density and Oxidation Kinetics of Fe-Si-B Alloys, J. Less-Commmon Met., 1978, 67(2), p 399-405

45. G. Lang, Effect of Alloying Elements on the Surface Tension of High Purity Aluminium, Aluminium, 1974, 50, p 731-734 (in German)

46. S.I. Popel, V.N. Kozhurkov, and A.A. Zhukov, Izv. Akad. Nauk SSSR Met., 1975, 5, p 69 (in Russian) cited in S.I. Popel, T.V. Zakharova, and V.A. Kozhevnikova, Density, Surface Tension and Adhesion to Iron of Pb-Sn Melts, Prot. Met., 1976, 12(4), p 423-425

47. L. Goumiri, J.C. Joud, P. Desre, and J.M. Hicter, Tensions Superficielles d'Alliages Liquides Binaires Présentant un Caractère Dimmiscibilité: Al-Pb, Al-Bi, Al-Sn et Zn-Bi, Surf. Sci., 1979, 83, p 471-486 (in French)

48. C. Garcia-Cordovilla, E. Louis, and A. Pamies, The Surface Tension of Liquid Pure Aluminium And Aluminium-Magnesium Alloy, J. Mater. Sci., 1986, 21, p 2787-2792

49. L. Goumiri and J.C. Joud, Auger Electron Spectroscopy Study of Aluminum-Tin Liquid System, Acta Metall., 1982, 30, p 1397-1405

50. A. Pamies, C. Garcia Cordovilla, and E. Louis, The Measurement of the Surface Tension of Liquid Aluminium by Means of the Maximum Bubble Pressure Method: The Effect of Surface Oxidation, Scr. Metall., 1984, 18, p 869-872 
51. V. Sarou-Kanian, F. Millot, and J.C. Rifflet, Surface Tension and Density of Oxygen-Free Liquid Aluminum at High Temperature, Int. J. Thermophys., 2003, 24(1), p 277-286

52. J.M. Molina, R. Voytovych, E. Louis, and N. Eustathopoulos, The Surface Tension of Liquid Aluminium in High Vacuum: The Role of Surface Condition, Int. J. Adhesion Adhesives, 2007, 27, p 394401

53. N. Eustathopoulos, M.G. Nicholas, B. Drevet, Wettability at High Temperature, Pergamon Material Series, Pergamon, Oxford, 1999 